\title{
Case Report: Single Mothers' Tendency to Remarry and the Obstacles: A Case on Basic Theory
}

\author{
Maryam Eskafi $^{* *}$ (D), Mandana Yousefi ${ }^{2}$ (D) \\ 1. Department of Sociology, Faculty of Litrature and Humanities Sciences, Gonabad Branch, Islamic Azad University, Gonabad, Iran \\ 2. Department of English, Faculty of Litrature and Humanities Sciences, Quchan Branch, Islamic Azad University, Quchan, Iran.
}

\begin{tabular}{l|l}
$\begin{array}{c}\text { Use your device toscan } \\
\text { and read the artice online }\end{array}$ \\
Citation Eskafi M, Yousefi M. Single Mothers' Tendency to Remarry and the Obstacles: A Case on Basic Theory. Journal of \\
Research \& Health. 2021; 11(2):131-138. http://dx.doi.org/10.32598/JRH.11.2. 1368.3
\end{tabular}

\section{(1) (3)}

Article info:

Received: 29 Jun 2019

Accepted: 01 Feb 2020

Publish: 01 Apr 2021

\section{Keywords:}

Single parent, Remarriage, No return feminitity, Obstacles of remarriage

\section{ABSTRACT}

Background: Human beings are a social species. Marriage is an important step in human life because many of the main human needs are met after marriage. The purpose of this research was to study the tendency of single mothers to remarry, and the variables and barriers involved. The conceptual framework for this study involves a mix of social concept theories, Maslow's necessity hierarchy, Eisen's reasoning theory, and Lewin's Psychological Field Theory on barriers.

Methods: The current study used a qualitative technique (fundamental theory) for coding, editing, categorizing, and analyzing information. To the best of our knowledge, a fundamental theory analytical technique has been used to classify and evaluate information. For this purpose, eleven single mothers (all with kids) were surveyed in Gonabad city. Despite their inclination to build a connection between structure and interaction and by mixing information with theory, the scientists attempted to design the procedure for mothers' celibacy.

Results: The data analysis included coding of three main core levels, eleven first-category items, and 27-second category items. The main focus was feminism, social isolation, inappropriate cultural structure, social suicide, and the display of spiritual and material life.

Conclusion: The results showed that single mothers not only tend to remarry but also seriously need to be married. However, the inner and outer variables stop them from remarrying. Therefore, they are looking for a replacement that leads to their social isolation. Facilitative strategies to pave the way for their remarriage can therefore assist them considerably.

\section{Introduction}

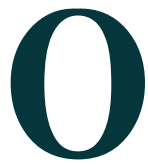

ne of the common events in present societies is an increase in the number of single mothers, who should do their husband's duties, as well. However, this social issue of single mothers is associated with the financial, social, and cultural situation of society. Ac- cording to Hart [1], most people in Australia experience widowhood and remarriage.

Widowhood today occurs mainly for the elderly, but a considerable mortality rate was observed in young adults in the mid- $19^{\text {th }}$ century. The present society has confronted the need for seniors and orphans at the national and the local levels. Kevin Shafer [2] stated that

\section{"Corresponding Author:}

Maryam Eskafi, PhD.

Address: Department of Sociology, Faculty of Litrature and Humanities Sciences, Gonabad Branch, Islamic Azad University, Gonabad, Iran Phone: +98 (915) 3221003

E-mail: mesafi@yaoo.com 
in the latest decades, divorce and its subsequent remarriage have played an important role in American family life. He assessed the role of gender differences in remarriage by focusing on females. In a survey [3], an analysis of the impact of female individuality variables on their tendencies to remarriage was carried out. The extrovert and flexible females were found to be more likely to remarry. In the meantime, the findings of another research [4] in the UK showed that elderly married males were more willing than females to have a fresh partner after death and remarry. The reason could be due to the fact that females consider their prior spouse to be perfect and they have the fear of a wrong choice. It has been also shown that [5] the choice of single moms to remarry has been affected to a large extent by social issues, which reduces the marriage rate of women compared with that of males. Because of their inclination to remarry, the number of kids in the earlier marriage, the point of view of the parents, and parents' social and job status have been regarded in previous studies [6]. Because in Iran and many other nations, this is a significant issue, it should be given particular attention. The important variables for remarriage include sex and the number of children [7-9]. Special attention has also been given to financial, social, and psychological issues [10]. Chung in his thesis offered a broader view of remarriage in the United States.

The results of some preliminary exploratory interviews with single mothers in Gonabad showed that compulsion, control, and cultural pressures that intensify the adverse and traditional views of the people and their approach to these females can be an important psychological problem. A short study [11] on the economic status of single mothers has shown that their remarriage has been largely avoided by the cultural aspects to address the multiple issues of these females. This issue has been overlooked; however, their financial status was attempted to compensate. Nonetheless, this measure could not resolve their issues. The marriage of single women can restore their family life by properly preparing a cultural atmosphere. As some researchers [12] suggested, the economic level of single mothers cannot fix their issues entirely, as their families have their own financial problems. These issues are often confronted by both married males and females, but they can be tolerated because they benefit from their spouses (non-financial needs) that in turn makes it simpler for them to deal with economic issues. Malek Motiee [13] verified this finding, as well.

In some areas of Iran, such as Gonabad city, the issue is more serious and evident because of imagination and stereotypes prejudiced. An exploratory interview with Imam Khomeini Deputy Director and the Sub-Secre- tary for Family Empowerment in Gonabad showed that 1800 single mothers out of seventy thousand people are covered. This demonstrates how necessary a qualitative study is to address the following research questions that may assist single mothers in more stable family life:

- Do single mothers have a tendency to remarry?

- If yes, what are their major motives for remarriage?

- Why don't the single mothers remarry in the investigated sample?

- What are the cultural obstacles for single mothers' remarriage?

\section{Methods}

A qualitative methodology based on the interpretive paradigms of the scientists was used. This strategy is intended to provide an assessment based on context, situation, and context, in relation to responding to the circumstances, circumstances, and people being investigated [14], to provide a fresh knowledge of the unknown problems, and profound knowledge of the details of such events [15]. Meanwhile, the answer to study issues requires extensive and profound knowledge of the motivation of single mothers, and also their social, cultural, and economic experiences.

Of the eighteen individuals chosen for the interview, only 11 were examined in the research so that they were asked to be present to transcribe the interviews in order to protect the right to privacy. As the information was gathered, all possible interpretations should be evaluated concurrently. After fully transcribing the interviews, the analysis began by dividing the information into separate meaning units. When the information gathered by these interviewees was saturated, the information collection stopped. The text was then analyzed line by line to determine whether a piece of information or unit was part of a particular concept or a representation or an example of it. This included the use of specific coding methods known as open coding [16]. In the next phase, axial coding was abstracted as a single category [16] for the concepts with comparable interpretation and meanings. Finally, each information was compared with other comparable information that appeared to fall within the same category to determine the overall ideas (selective coding) [16]. In the basic theory, the subordinate ideas are eventually linked to the primary superior ideas expressing the causal conditions, phenomena, settings, and conditions for the intervener, interactive, and counteractive strate- 
gies for each other and the implications [17], which resulted in 5 general abstracted ideas. It must be mentioned that in this grounded theory technique, the reliability of the three coding steps is achieved using three individuals for coding processes whose definitive accepted ideas and categories were chosen. In addition, interviewees were often consulted to ensure that the concepts chosen were exactly of their mental significance for the validation of the information, and the choices were taken only when they were verified by the respondents. In conclusion, the information was analyzed. This is an important step in the qualitative study, in which concepts derived from the collected data are linked to abstract concepts of the higher-order. For novice researchers facing enormous unorganized information and not sure of important achievements, this could be a confusing and worrisome part of qualitative research. This feature confirms the dedication to the trustworthiness of the analytical process rule [18].

\section{Results}

The obtained information showed that the majority of females had a traditional form of marriage. As shown in Table 1, over half of the females were married at the age of 17 years or under and had unemployment or part-time employment. In the meantime, more than $27 \%$ had no kids, $36 \%$ had only one, $18 \%$ had two kids, and almost $9 \%$ had three kids or more.

The researchers finished the analyses with several key conceptions by providing a thorough conceptualization, open, axial, and selective coding, and the subsumption of comparable classifications into a key idea. These included "efficient causes for the inclination to remarry", "external factors of failure to remarry", "causes of failure to remarry (inner variables)", "taken steps (excluding marriage)", and "the implications of failure to remarry".

\section{Causal conditions (tendency to remarry)}

\section{No answer to feminine feelings}

The Interviewees' answers indicated that the single mothers had a tendency and significant causes to remarry, and they still appreciate their feminine feelings as they have lost their husbands when they were young (death or divorce). Their need to have a connection with the other sex was one of the factors. The psychological suffering of a missing wife and isolation is created through this caressing need. "The husband as a social leader", was the second key idea that indicates that a widowed or divorced female in addition to the associated suffering and harm, had an adverse imagination and talked about social exclusions making remarriage a final resort for single parents. The third reason was financial needs. This is triggered by variables, such as job and earnings, difficulty in gaining a livelihood, a lack of privacy, a lack of self-contained accommodation, and the fact that parents have been forced to go along with their kids, which have led single mothers to lose their independence in bringing up their children.

\section{Contextual conditions}

\section{Inappropriate cultural structure}

Despite their pressing need, most single mothers do not remarry. The causal and contextual circumstances are mainly responsible for this. With respect to the contextual circumstances, inappropriate cultural structure generates two main challenges for them; 'the dominant cultural atmosphere' and 'hardship (Osr va Haraj)'.

The prevailing cultural environment is where these females live and they have special norms and values that are so powerful making them able to reveal their behavioral forces and decrease resistance. The impact of the environment on the human being and his behavior is obvious. The findings of the interviews showed that all of these individuals were extremely influential owing to their familiarity with the environment and their minds also tended to make atmosphere-oriented choices. The cliché ideas are one of the components that constantly exist in this environment that impede human choices. Cliché is a shallow, illogical concept or imagination of a particular problem that is unknowingly produced in the mind of people as a result of repeating itself often through communication with members of society or the media. It prevents the individuals who own it from having adequate recognition and is obvious as the worry and anxiety of women.

A culturally inappropriate picture of the remarriage to the single mother (particularly the one who has a kid) was developed by our respondents and their families and relatives (near and far), and those who do not dare remarry in order to avoid adverse judgments. It takes many years to modify this cliché. The concealed results of this picture cause severe emotional and psychological harm in single parents. This particular and inflexible picture, which dominates the minds of the other important participants, influenced their different decisions. Whenever there is an opportunity for remarriage, they cannot make the right decision and judgment and consider the facts. The laws on the termination of custody and the pension of the mothers after remarriage have also deepened this. While the kids from the earlier marriage and the circum- 
Table 1. Demographic information of the samples $(n=11)$

\begin{tabular}{lcc}
\hline Demographic Information & No. (\%) \\
\hline Marriage age & 16 & $3(27.3)$ \\
& 18 & $3(27.3)$ \\
& 20 & $1(9.1)$ \\
Occupation & 22 & $1(9.1)$ \\
& Household & $3(27.3)$ \\
& School attendant & $5(45.4)$ \\
& Shopkeeper & $1(9.1)$ \\
& Bank employee & $3(27.3)$ \\
& University staff & $1(9.1)$ \\
& No children & $1(9.1)$ \\
\hline Number of children & One child & $3(27.3)$ \\
& Two children & $4(36.4)$ \\
& More than three & $2(18.2)$ \\
& & $1(9.1)$ \\
& & $1(9.1)$ \\
\hline
\end{tabular}

IRPA

stances connected with them are severe barriers despite their inclination and need for remarriage.

\section{Causal conditions (obstacles for remarriage)}

\section{Social suicide}

Although the participants tended to remarry, causal factors stopped the eager females from doing this temporarily and severely. Despite their basic needs, these women are physically alive but psychologically ill and have buried their desire and enjoyment in order to fulfill their parents' demands. To prevent this social situation, the background conditions, including the serious culturally improper framework can be mentioned. This suicide is linked to maternal features, such as sacrifice for others and volatile confrontation. The former is a romantic folly, to which the single mothers adapt themselves so that because of their profound affection for their prior spouse and their inability to find another one, they do not feel confident or interested. They believe that maternal love is developed as a consequence of caring for the kids and maintaining them safe from damage, which in turn leads to "forgetting in favor of the child". This forgetfulness makes them temporarily replace the connection with the kids or employment and education for their untaken wife. Their previous negative experiences and the emotional and psychological damage result in the fear that they cannot tolerate another harm caused by remarriage.

\section{Coping strategies}

Single parents use spiritual and material to show off

If there is a tendency to remarry, but the background and causal circumstances prevent a remarriage of a single mother, other strategies in life will be developed. Some bring spiritual substitutions while others take material substitutions inappropriately. The relevant material strategies called expressive interactions are seen as factors strengthening social resources and spiritual values. Spiritual and inappropriate strategies as "instrumental interactions" are not only developed to meet the requirements of the person by expressing himself excitingly. Table 2 presents the information on these items. 
Table 2. Results of open, axial, and selective coding

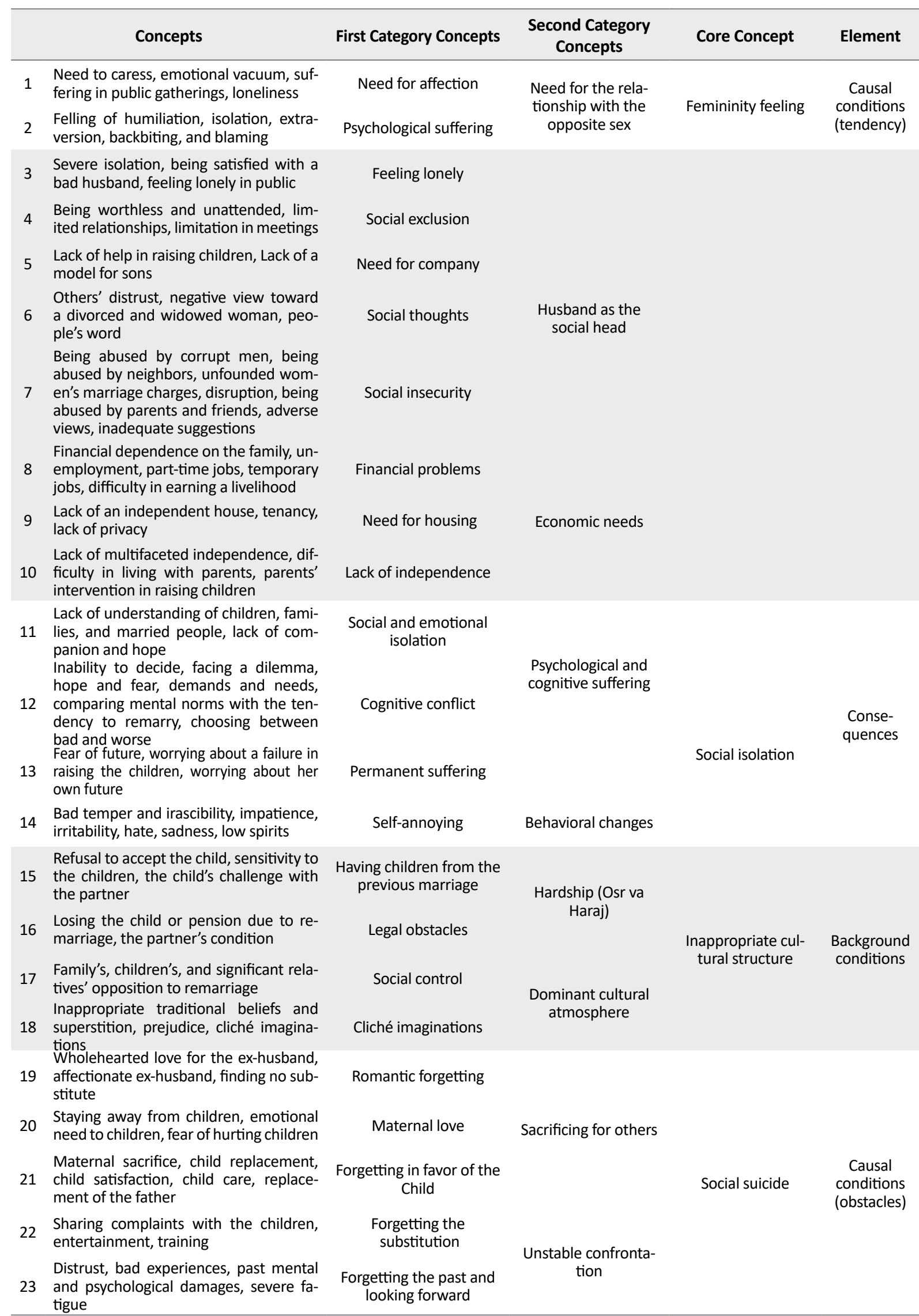




\begin{tabular}{|c|c|c|c|c|c|}
\hline \multicolumn{2}{|r|}{ Concepts } & \multirow{2}{*}{$\begin{array}{l}\text { First Category Concepts } \\
\text { Exciting self-expression }\end{array}$} & \multirow{2}{*}{$\begin{array}{c}\text { Second Category } \\
\text { Concepts } \\
\begin{array}{c}\text { Instrumental interac- } \\
\text { tions }\end{array}\end{array}$} & \multirow[t]{2}{*}{ Core Concept } & \multirow[t]{2}{*}{ Element } \\
\hline 24 & $\begin{array}{l}\text { Making verbal communication fre- } \\
\text { quently with important males, dating } \\
\text { with married fathers and pawns }\end{array}$ & & & & \\
\hline 25 & $\begin{array}{l}\text { Show off for loved married males, re- } \\
\text { stricted physical interaction with strang- } \\
\text { ers, annoying men using phone and } \\
\text { telegram, illegal sexual relationship }\end{array}$ & $\begin{array}{l}\text { Satisfying unnecessary } \\
\text { legitimate needs }\end{array}$ & tions & $\begin{array}{l}\text { Spiritual and mate- } \\
\text { rial show off }\end{array}$ & $\begin{array}{l}\text { Coping } \\
\text { strategies }\end{array}$ \\
\hline 26 & $\begin{array}{l}\text { Participation in thankful gatherings, at- } \\
\text { tending charity assemblies, strengthen- } \\
\text { ing the relationships with God, spiritual } \\
\text { journeys and pilgrimages, talking to God }\end{array}$ & $\begin{array}{c}\text { Strengthening spiritual } \\
\text { values }\end{array}$ & $\begin{array}{l}\text { Expressive interac- } \\
\text { tions }\end{array}$ & & \\
\hline 27 & $\begin{array}{l}\text { Trying to build on uniform networks of } \\
\text { friendship, short journeys with similar } \\
\text { friends, great emotional happiness, } \\
\text { long-lasting families, supporting uni- } \\
\text { form people, laughing }\end{array}$ & $\begin{array}{l}\text { Strengthening social } \\
\text { assets }\end{array}$ & & & \\
\hline
\end{tabular}

\section{Consequences of failure to remarry}

\section{Social isolation is one of the consequences of failure to remarry}

None of the approaches suggested by the subjects could offset the single parents' demands and needs, except remarriage (as affirmed by the respondents). Although these strategies somehow helped them meet all their needs and live their painful lives, their social isolation and loneliness have become so strong that they cannot tolerate and forget the resulted psychological and social insecurity. Thus, "psychological and cognitive suffering" and "behavioral modifications" in their future lives are two significant factors leading to the inability to remarry. These effects depend on the character of the person, whether psychological or cognitive. Social and psychological loneliness results from the absence of empathy and forms an integral part of their lives. The mental pain is continuous and puts them in a position (an inevitable behavioral dispute) to choose between the evil and the worse due to current circumstances. Regarding behavioral modifications, continuous pain substitutes sorrow for joy in life and manifests itself as masochism in behaviors, i.e. aggression, anger, impatience, and sadness at work. The present scenario is summarized in Figure 1 based on the grounded theory approach.

As can be seen, the six main variables included the causes, background conditions, inner and emotional factors, phenomena, applicable strategies, and the implications.

According to the outcomes of the three phases of coding, the open coding ideas contained multiple ideas that in particular, multiply the widow's need for a wife, the improper cultural structure for a divorced and homeless person, and the woman's social need for the wife. The findings of another research conducted in Mashhad verified this finding, in which $50 \%$ of single mothers in Mashhad were likely to remarry [13]. This result is also in line with that of Orojloo and Khodabakhshi [3]. These results also correspond to those of Fish Byne Aysen's Tendency Theory, which reported a tendency for social standards and orientation. Furthermore, psychological theories of social interaction argue that the lack of a woman generates a number of emotional and social questions for a woman. Many national and international studies have discovered that it is so hard to be a single mother, especially when she is the head of the family. Children and their education and future lives are the main issues for a single mother because only mothers can be responsible for financial issues. Any debate of single mothers' issues is often linked to their economic issues and possible methods to increasing economic level. Psychological and economic issues of single mothers have been widely studied $[9,10]$ and it has been shown that this is a global problem. One of the threats to the family structure was the presence of single parents, particularly when single mothers raise kids [6]. This is also confirmed by the theories of socialization and functionalism because the mother and father each play a distinctive role and the death of a spouse, in addition to affecting his/ her spouse, can cause severe mental, psychological, and social damages to kids.

The information obtained from categorization, evaluation, and interpretation of the data also showed that despite a high tendency and the necessity for single parents to remarry, certain circumstances, such as improper social structures, make them develop inner feelings and emotions that 


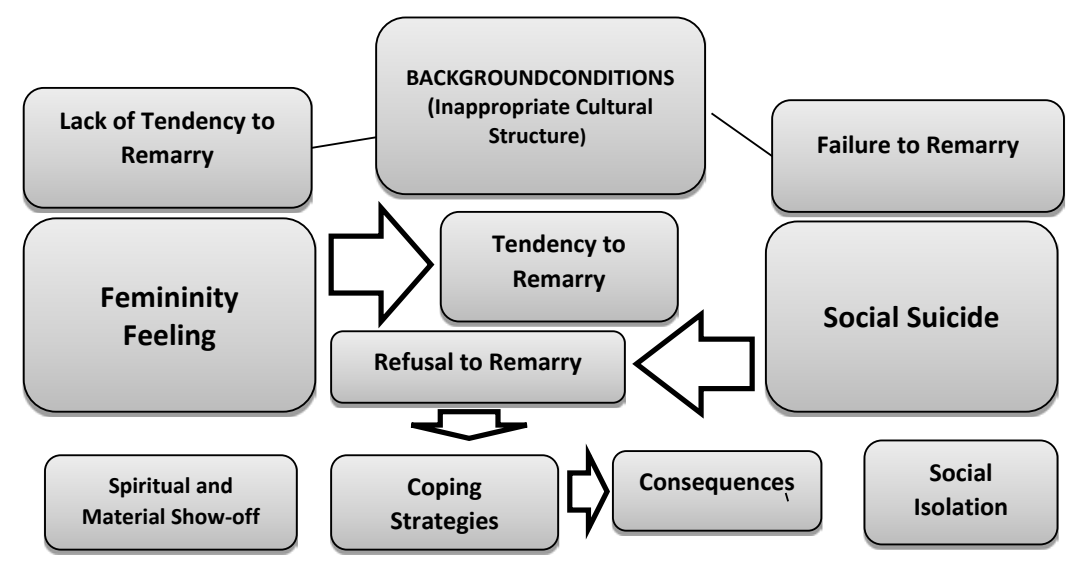

Figure 1. Summary of the current situation

motivate them to forget their requirements. These undesirable circumstances that include hardship (Osr va Haraj), as well as legal constraints and social control, and cliché imagination, lead to the development of a social suicide, which in turn manifests itself as a finding substitute for romantic needs in favor of the children, and forgetting future. Thus, the most basic way of empowering a single mother and the most important approach to improve her life is lost. The inadequate interference of social network members in the choices of the people regarding their own lives can be seen by studying social network theories. This is also confirmed by Dorklim's Theory of Social Imagination and social control theories. According to the cliché imaginations in Gonabad, the remarriage of single mothers is an unwanted action that puts them in conflict with others. Based on Festinger's Conflict Theory, a person develops a certain cognitive inconsistency as a consequence of this cliché imagination, which makes him choose from bad and worse. According to this theory, both individuals and the important others need to be verified. They only confirm themselves and not others when they are likely to remarry, leading to a tension that prevents them from making the correct choice. Because it is difficult to meet the need, according to Maslow's theory, the worse effects will be assessing the advantages. There is a lengthy gap between trend and action. The preventive function of the family environment and the cliché imaginations is considering remarriage of single mothers and their spouses dreadful and disgusting. This is the main obstacle in the remarriage of women in Gonabad. Legal obstacles have also been mentioned by some other studies [5, 6], as well. Psychological and cognitive pain and damaging modifications of behavior as selfishness and continuous pain include the implications of ignoring these processes and requirements. As several other studies stated [7, $8,11]$, experiences of remarried persons demonstrate that their lives are mentally healthier and happier.

\section{Conclusion}

In short, this research indicated that single mothers tend not only to remarry, they also showed their feminine need for a husband. As the results of the interviews, remembrance could solve most of its issues, even if these mothers have financial issues. This is because single mothers suffer the lack of job through clichés despite all their sacrifices and patience as a single parent. They expect their kids, families, and other important people to comprehend and judge them correctly, as they do not make sensible decisions or are not against their cliché ideas. Many studies have proposed economic support to solve mother's issues while all the participants of this study were employed and could help their families, but all stressed their pressing need for remarriage and this confirms that solving financial problems cannot satisfy all of their requirements. It is therefore proposed that efforts should be made to purify the minds of the people from such social inadequate cliché ideas through social facilitation and through collaboration with accountable and associated organizations, such as the municipality, the welfare organization, the Aid Committee, mosques, and cultural centers. In the meantime, they should pave the way for single mother to remarry by logically assisting them, particularly in smaller groups, to make and provide a better environment for them. We urgently need to adopt the necessary steps and establish the appropriate circumstances for the remarriage of single mothers in society.

\section{Ethical Considerations}

\section{Compliance with ethical guidelines}

This study was approved by the Ethics Committee of the Islamic Azad University, Gonabad Branch (No. 09/20/2/1669). 


\section{Funding}

This research did not receive any grant from funding agencies in the public, commercial, or non-profit sectors.

\section{Authors' contributions}

Study design, data collection and analysis: Maryam Eskafi Nogani; Manuscript preparation: Both authors.

\section{Conflict of interest}

The authors declared no conflict of interest.

\section{References}

[1] Hart S. Widowhood and remarriage in colonial Australia. [PhD dissertation]. Australia: University of Western; 2009. https:// research-repository.uwa.edu.au/en/publications/widowhoodand-remarriage-in-colonial-australia

[2] Shafer KM. Gender differences in remarriage: Marriage formation and assortative mating after divorce [PhD. dissertation] Ohio: The Ohio State University; 2009. http:/ /rave.ohiolink.edu/ etdc/view?acc_num $=$ osu1247497348

[3] Orojloo S, Khodabakhshi Koolaee A. Comparison between personality traits and hope among female-headed households with or without tendency towards remarriage. Salamat Ijtimai (Community Health). 2016; 3(2):101-10. https://journals.sbmu.ac.ir/ ch/index.php/ch/article/view/11768

[4] Bennett KM, Arnott L, Soulsby LK. "You're not getting married for the moon and the stars": The uncertainties of older British widowers about the idea of new romantic relationships. J Aging Stud. 2013; 27(4):499-506. [DOI:10.1016/j.jaging.2013.03.006] [PMID]

[5] Lyn P, Helen C. The stigmatisation of widows and divorcees (janda) in Indonesian society. Indones Malay World. 2016; 44(128):1-6. [DOI:10.1080/13639811.2015.1111647]

[6] Charati E, Esfandiarpour J. Nezaratizadeh M. Shahabi M. Attitudes of women heads of households to remarriage, Environ Conserv J (ECJ). 2015; 16(SE):25-32. [DOI:10.36953/ECJ.2015.SE1604]

[7] Watson WK, Bell N, Stelle CJ. Women narrate later life remarriage: Negotiating the cultural to create the personal. J Aging Stud. 2010; 24(4):302-12. [DOI:10.1016/j.jaging.2010.07.002] [PMID] [PMCID]

[8] Aktürk BA, Fisiloglu H. Marital satisfaction in Turkish remarried families: Comparison among marital status, effect of stepchildren and contributing factors. J Divorce Remarriage. 2009; 50(2):119-47. [DOI:10.1080/10502550802365755]

[9] Kotwal N, Prabhakar B. Problems faced by single mothers. J Soc Sci. 2009; 21(3):197-204. [DOI:10.1080/09718923.2009.11892771]

[10] Kebele AZ, Abebe YM. Lived experiences of divorced women in rural Ethiopia: A special focus in Hulet Eju Enessie Woreda. Int J Politic Sci Dev (IJPSD). 2015; 3(6):268-81. https:/ / www.academicresearchjournals.org/IJPSD/PDF/2015/June/Abebe.pdf
[11] Muh-Chung M. Three essays on remarriage [PhD. dissertation]. Chicaco: The University of Illinois; 2016. https:// knowledge.uchicago.edu/record/453

[12] Alexander AC, Jalalzai F. Symbolic empowerment and female heads of states and government: A global, multileve analysis. Politics Groups Identities. 2018; 8:24-43. [DOI:10.108 0/21565503.2018.1441034]

[13] Malek Motiee Z. The tendency to remarry for the divorced women under the auspices of Imam Khomeini Relief Committee in Mashhad City in 2008 and its effective factors [MA thesis]. Mashhad: Ferdowsi University; 2009. https://elmnet. ir/article/10470179-39391/\%DA\%AF\%D8\%B1\%

[14] Mohammadpour A. Meta-method: Philosophical and practical foundations of combined research method in social and behavioral sciences. Tehran: Jameh-Shenasan Publication; 2010. https:/ / www.gisoom.com/book/11047101/

[15] Miles MB, Huberman AM, Saldana J. Qualitative data analysis: A methods sourcebook ( $3^{\text {rd }}$ ed.). Los Angeles, CA: Sage; 2014. https://www.amazon.com/Qualitative-DataAnalysis-Methods-Sourcebook/dp/1452257876

[16] Hariri, N. Principles and methods of qualitative research. Tehran:Islamic Azad University, Scienceand Research Branch; 2006. https://www.gisoom.com/book/1786834/\%DA

[17] Creswell, JW. Research design: Qualitative, quantitative, and mixed methods approaches (4th ed). Thousand Oaks, CA: SAGE Publications; 2014. http://fe.unj.ac.id/wp-content/uploads/2019/08/Research-Design_Qualitative-Quantitative-and-Mixed-Methods-Approaches.pdf

[18] Nowell LS, Norris JM, White DE, Moules NJ. Thematic analysis: Striving to meet the trustworthiness criteria. Int J Qual Methods. 2017; 16(1):1-13. [DOI:10.1177/1609406917733847] 